\title{
Rehabilitative treatment of cleft lip and palate: experience of the Hospital for Rehabilitation of Craniofacial Anomalies/USP (HRAC/USP) - Part 4: Oral Rehabilitation
}

\author{
José Alberto de Souza FREITAS ${ }^{1}$, Ana Lúcia Pompéia Fraga de ALMEIDA², Simone SOARES ${ }^{2}$, Lucimara Teixeira \\ das NEVES ${ }^{3}$, Daniela Gamba GARIB ${ }^{4}$, Ivy Kiemle TRINDADE-SUEDAM ${ }^{3}$, Renato Yassutaka Faria YAEDÚ ${ }^{5}$, Rita de \\ Cássia Moura Carvalho LAURIS ${ }^{6}$, Thais Marchini OLIVEIRA ${ }^{7}$, João Henrique Nogueira PINTO ${ }^{8}$
}

\begin{abstract}
1- DDS, MSc, PhD, Superintendent, Hospital for Rehabilitation of Craniofacial Anomalies and Full Professor, Department of Stomatology, Bauru School of Dentistry, University of São Paulo, Bauru, SP, Brazil.

2- DDS, MSc, PhD, Assistant Professor, Department of Prosthodontics, Bauru School of Dentistry and Hospital for Rehabilitation of Craniofacial Anomalies, University of São Paulo, Bauru, SP, Brazil.

3- DDS, MSc, PhD, Assistant Professor, Department of Biological Sciences, Bauru School of Dentistry and Hospital for Rehabilitation of Craniofacial Anomalies, University of São Paulo, Bauru, SP, Brazil.

4- DDS, MSc, PhD, Associate Professor of Orthodontics, Department of Pediatric Dentistry, Orthodontics and Community Health, Bauru School of Dentistry and Hospital for Rehabilitation of Craniofacial Anomalies, University of São Paulo, Bauru, SP, Brazil.

5- DDS, MSc, PhD, Assistant Professor, Department of Stomatology, Bauru School of Dentistry and Hospital for Rehabilitation of Craniofacial Anomalies, University of São Paulo, Bauru, SP, Brazil.

6 - DDS, MSc, Orthodontist, Dental Division, Hospital for Rehabilitation of Craniofacial Anomalies, University of São Paulo, Bauru, SP, Brazil.

7- DDS, MSc, PhD, Assistant Professor, Department of Pediatric Dentistry, Orthodontics and Community Health, Bauru School of Dentistry and Hospital for Rehabilitation of Craniofacial Anomalies, University of São Paulo, Bauru, SP, Brazil.

8- DDS, MSc, PhD, Prosthodontist of the Dental Division of the Hospital for Rehabilitation of Craniofacial Anomalies, University of São Paulo, Bauru, SP, Brazil.
\end{abstract}

Corresponding address: Ana Lúcia Pompéia Fraga de Almeida - Hospital de Reabilitação de Anomalias Craniofaciais - Periodontia - Rua Silvio Marchione, 3-20 - Bauru - SP - Brasil - 17090-012 - Phone: 551432358081 - e-mail: analmeida@usp.br

Received: January 27, 2013. - Modified: March 13, 2013 - Accepted: March 14, 2013

\section{ABSTRACT}

\begin{abstract}
Treatment of patients with cleft lip and palate is completed with fixed prostheses, removable, total, implants and aims to restore aesthetics, phonetics and function and should be guided by the basic principles of oral rehabilitation, such as physiology, stability, aesthetics, hygiene and the expectations of the patient. In order to obtain longevity of a prosthetic rehabilitation, the periodontal and dental tissue as well as the biomechanics of the prosthesis are to be respected. The purpose of this article is to describe the types of prosthetics treatment, which are performed at HRAC/USP for the rehabilitation of cleft area in adult patients.
\end{abstract}

Key words: Cleft palate. Cleft lip. Periodontal diseases. Dental prosthesis. Dental implants.

\section{INTRODUCTION}

The oral rehabilitation of individuals with cleft lip and palate is directly related to the severity of anatomical and functional alterations determined by the malformation and the age at treatment onset ${ }^{13}$. The ideal treatment of the cleft area is closure by bone graft and orthodontics ${ }^{12}$. When this is not feasible, many cases are solved with prosthetic rehabilitations. According to Mazaheri, $60 \%$ of individuals with clefts will require some type of denture, and this percentage tends to increase if the cleft affects the alveolar ridge ${ }^{17}$.

The dentures may be fixed or removable, toothor implant-supported, and aim to reestablish the aesthetics, phonetics and function ${ }^{22,23}$ and their indication depends on the dental, periodontal and bone conditions and the maxillomandibular relationship ${ }^{21}$.

Teeth close to the cleft area may present adverse conditions for restorative treatment, such as presence of crowding, rotation, crown and root malformations ${ }^{24}$, partial eruption of teeth, presence of frenula ${ }^{1}$, absence of keratinized mucosa ${ }^{1}$, 
high prevalence of gingival recession ${ }^{2,3,5}$, shallow vestibule $^{4}$, difficult hygiene ${ }^{6}$, and the condition of supporting periodontal tissue.

Other aspects to be considered are the interarch discrepancy (in the different segments of the maxillary arch) and maxillomandibular discrepancies, which require orthodontic treatment in most cases. However, orthodontics is not always able to solve cases with marked discrepancy. In these situations, orthognathic surgery is indicated and should be planned in combination with the prosthodontist, to establish the final predictability of the outcome ${ }^{14}$.

In individuals with cleft lip and palate, occlusal problems are observed due to these discrepancies, such as absence of anterior guidance, alteration in vertical dimension and lack of occlusal stability ${ }^{11}$.

The poor oral hygiene is a goal in the rehabilitation process, because the early tooth loss may further worsen the complexity of rehabilitation ${ }^{17}$.

Achieving aesthetic outcomes and the search for a normal condition are challenging to the professional, because the presence of lip frenula, deficiency of bone tissue and keratinized mucosa may cause serious problems for maintenance of the prosthetic work.

An important characteristic to be considered by the professional is the presence of palatal fistulas, which have a direct influence on impression taking. The fistula is a communication between the oral and nasal cavities ${ }^{22}$ that should be temporarily closed without damage to the anatomy of tissues to be copied in the impression (e.g. lubricated gauze or aluminum foil). Thus, selection of the impression material is important because it may penetrate this region causing difficulty in removal and discomfort to the individual. Therefore, more fluid materials should be avoided because if extrusion occurs through the fistula, the removal is troublesome and unpredictable.

The treatment should be guided by the basic principles of rehabilitation, including physiology, stability, aesthetics, hygiene conditions and the individual's expectations.

The physiological function of mastication, speech and swallowing should be restored by the occlusal and articular balance. The retention and stabilization of bone segments are important to maintain the results achieved by orthodontics.

The aesthetic function comprises an improvement of the profile at the upper lip and region and location (alignment) of the teeth. Individuals with cleft lip and alveolus usually present a low smile line, i.e. most individuals do not present exposure of teeth and gingival tissues on smiling, which facilitates the achievement of denture aesthetics even in the absence of bone or gingival tissue ${ }^{8,10}$.

Finally, the prosthetic rehabilitation contributes directly and positively to the psychological aspects of the individual ${ }^{14,15,16}$.

The main prosthetic treatments involved in the oral rehabilitation of individuals with cleft lip and palate are fixed partial denture, removable partial denture, overlay denture, complete denture and implant-supported denture ${ }^{16,27}$.

Concomitant to the diagnosis and indication of dentures, periodontal principles should guide their planning and accomplishment, in either tooth- or implant-supported dentures, because no prosthetic work may be maintained without adequate periodontal health conditions. Thus the aim of this article is to describe the types of prosthodontic treatment that are conducted at the Hospital for Rehabilitation of Craniofacial Anomalies/University of São Paulo (HRAC/USP) for the rehabilitation of the cleft area in adult patients according to periodontal and prosthetics principles.

\section{TYPES OF ORAL REHABILITATION}

\section{ADHESIVE FIXED DENTURE (AFD)}

The AFDs were largely indicated in the 1970s, yet with the advent and consolidation of implants and the difficulties for their indication related to loss of bonding. Despite the evolution of adhesives, its utilization has been limited over time.

In individuals with cleft lip and palate, the indication remains because in some cases, the AFD is a satisfactory prosthetic solution. Its indication is primarily for small prosthetic spaces.

Provided that satisfactory conditions and favorable occlusion are present, the lateral incisor region may receive an AFD, which plays a predominantly aesthetic and phonetic function (Figures 1 and 2).

During denture fitting care should be given to the absence of contact on the lateral incisor in Central Relationship (CR), Maximum Intercuspation (MI) and during lateral and protrusive movements.

Indication of these dentures should also consider the basic principles of fixed dentures, including overjet and overbite (minimum $1 \mathrm{~mm}$ for both), and space for the framework - either in metal or ceramic, the abutment teeth should have enough enamel to allow preparation.

When aesthetic materials are indicated it is possible to use zirconia, ceramics or ceramicreinforced resins, however, the conventional adhesive dentures (metallic framework) are still widely employed for the treatment of these individuals.

The prosthetic space for placement of an AFD should be analyzed in vertical and horizontal directions, because the presence of a cleft in this region may cause an increase or decrease in the horizontal direction, so that only one tooth may 
be insufficient to restore the aesthetics and two teeth may not fit in the available space. Also in the vertical direction, due to the bone and consequent gingival loss, this region requires special care, because indication of conventional fixed or adhesive dentures should be comprised of a ceramic gingiva, which may preclude the indication of an AFD and guide the treatment for a conventional fixed denture.

The impression taking for cases of AFD is restricted to the indication of a material that may be able to copy details, and the technique concerns the manual capacity of each professional.

Other aspects to be considered are the cements available in the market, which require adhesion to the enamel and restorative material, otherwise the work would be impaired, with reduced life span.

\section{FIXED PARTIAL DENTURE (FPD)}

The treatment with FPD is still widely indicated, especially in cases of failure of the alveolar bone graft or when its indication is not possible ${ }^{26}$ (Figure $3)$.

When planning is initiated, after clinical and radiographic examination, the professional should achieve maxillary and mandibular dental casts and mount them in a semi-adjustable articulator to perform a diagnostic wax-up before the onset of the procedures. The wax-up aims at investigating the area to be restored, especially in individuals with clefts, because this space, as previously mentioned, may be too large for restoration with only one tooth or insufficient for placement of two teeth.

During planning, malpositioned teeth, with small roots and/or peg-shaped crowns may be extracted and the indication of periodontal surgeries should be considered and performed, if necessary.

Care related to the bone support of abutment teeth should receive special attention concerning the quantity of root inserted in the alveolar bone, which depends on the quantity of teeth to be replaced (bridges) to be favorable. The larger the number of bridges, more abutment teeth should be involved. The FPD 's aim is that resistance $(R)$ be greater than or equal to the force ( $F$ ) applied on the denture $-\mathrm{R} \geq \mathrm{F}$. Adequate pulp vitality or endodontic treatment should be analyzed, as well as the root/ crown ratio $(3 / 2)$.

In some situations, malpositioned teeth may be corrected after prosthetic preparation or endodontic treatment should be indicated, if necessary.

After endodontic treatment, the possibility of fabrication of a metallic cast, resin or ceramic post should be considered to allow retention of the crown to be placed.

The bone level of the abutment tooth close to the cleft establishes a critical relationship, because in some situations, due to the unfavorable root/ crown relationship inherent to teeth adjacent to a non-grafted cleft area, combined with periodontal problems or due to root alterations ${ }^{28}$, which may lead to indication for extraction.

The FPDs are indicated when implant placement is not possible, alveolar bone graft or re-graft failed, and in unfavorable conditions of abutment teeth and adjacent tissues.

The preparations of abutment teeth for FPDs are guided by biomechanical principles, in which

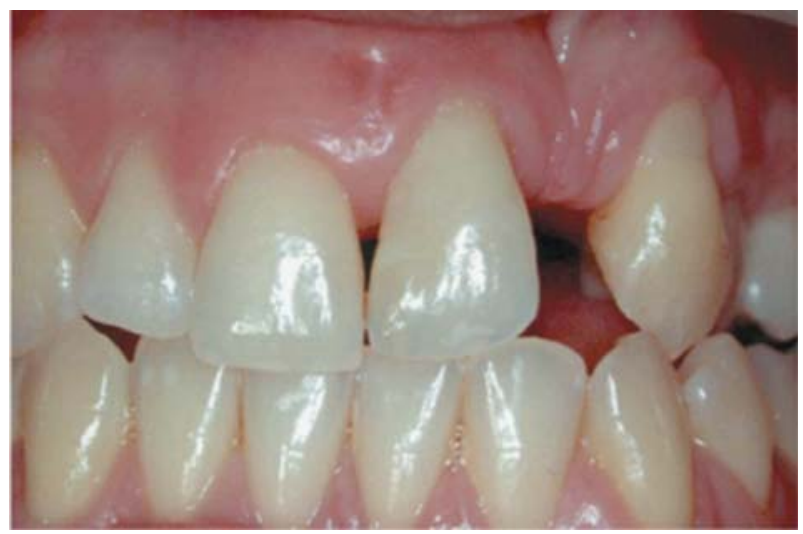

Figure 1- Frontal view with the absence of the lateral incisor

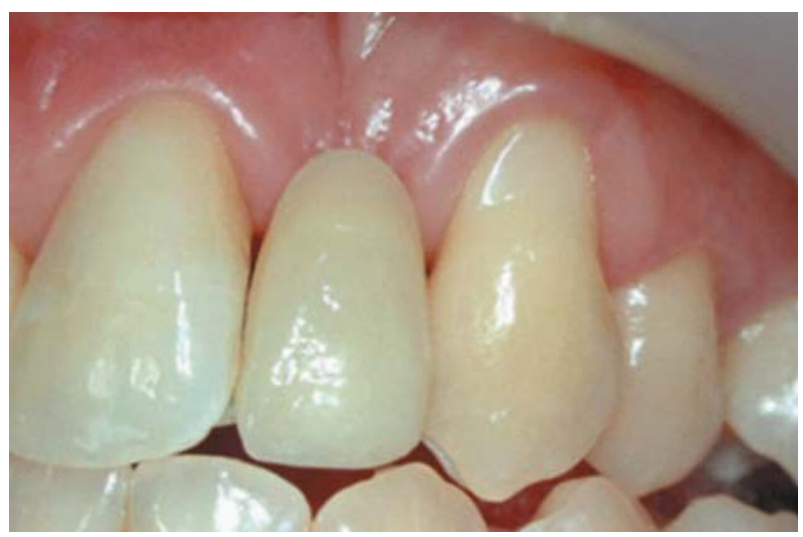

Figure 2- Rehabilitation of the lateral incisor through adhesive fixed denture

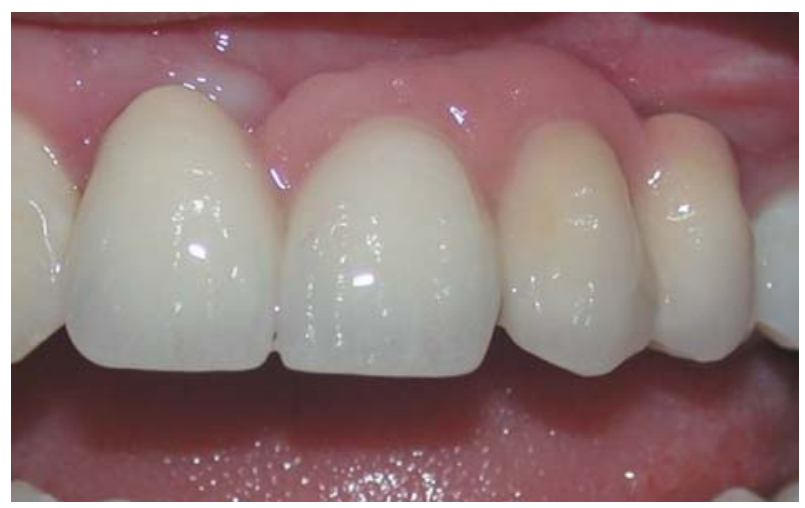

Figure 3- Treatment with fixed partial denture from right central incisor to left canine 
grinding is performed with diamond burs and the extent of grinding depends on the prosthesis indicated, either metal, ceramic and metal, or metal-free.

The impression technique depends primarily on the ability of the professional, impression material and location of the cervical limit. The ability of the professional allows achievement of impressions using impression cups (subgingival preparations with mercaptan and polyether), or light and putty addition or condensation silicone (double impression or relining and single or laminated impression), using subgingival cords.

\section{REMOVABLE PARTIAL DENTURE (RPD)}

For individuals with cleft lip and palate, the RPDs have been an important treatment option, because the maxillomandibular do not always allow the indication of an ideal treatment with fixed or implant-supported dentures. Due to the versatility and relative simplicity, they may be indicated in borderline and adverse situations (Figure 4).

These individuals usually present tissue deficiency in the middle facial third, both of the bone and soft tissue (lip). The mandible seems protruded, yet in fact there is retrusion of the midface, as a long-term effect of primary surgeries ${ }^{12}$.

The lip support of these individuals is impaired or inexistent, due to the poor alveolar ridge and the scar caused by surgical procedures. The removable dentures may be used effectively and satisfactorily in these situations.

Planning of the RPD should be combined to clinical and radiographic examinations and dental casts analysis in a surveyor. The analysis on the surveyor is important to allow changes in tooth anatomy aiming to enhance the denture retention.

The occlusal analysis should be considered, as well as the need of stabilization of posterior contacts and determination of the type and site of retainers, larger and smaller connectors, dental bar (if necessary) and selection of plastic teeth and base types.

The occlusion is very important, because the framework may allow reestablishment of the occlusal stability. Care should be taken to analyze the interocclusal distance when the vertical dimension of occlusion is increased, to achieve enough space for the placement of teeth.

The RPDs are further indicated for palatal closure in cases without surgical repair ${ }^{17}$.

\section{OVERLAY DENTURE (OD)}

This resource is indicated basically for individuals with cleft lip and palate, in extreme cases, with hypoplasia and marked retrusion of the maxilla with tooth loss and/or malpositioning, when it was not possible to indicate orthodontic treatment and orthognathic surgery.

In individuals with clefts, it aims to recover the maxillary arch that is retruded due to maxillary atresia, large maxillomandibular discrepancy, anterior open bite and missing or malpositioned teeth. Obviously this is not the ideal prosthetic solution, yet it allows completion of clinical cases with lip support and favorable vertical dimension.

These dentures provide functional and aesthetic benefits and satisfaction to the individual.

The planning follows the biomechanical principles of RPDs, modified especially in the metallic framework, which covers the ridge on the buccal aspect and is covered by the wax, providing lip support.

The impression procedure is restricted to the use of irreversible hydrocolloid or silicones (condensation or addition) to copy details of preparations made for fabrication of the RPD.

According to the treatment protocol at HRAC, all individuals receiving an $\mathrm{OD}^{14}$ should be previously evaluated and wear a provisional overlay denture to enhance the prognosis and design of the metallic framework (Figure 5).

Overlay dentures should be indicated in individuals with good oral hygiene or committed to follow the maintenance therapy, especially in case of susceptibility to caries and periodontal disease ${ }^{25}$ (Figure 6).

\section{COMPLETE DENTURE (CD)}

Due to alterations of the alveolar ridge of individuals with cleft lip and palate, the rehabilitation

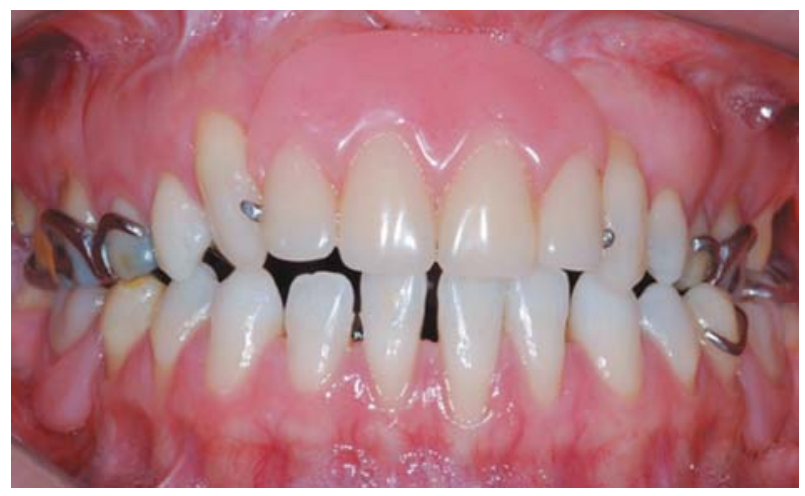

Figure 4- Cleft area rehabilitated with removable partial denture

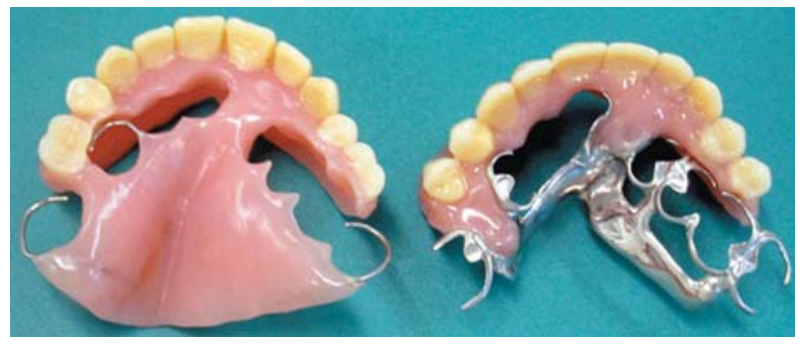

Figure 5- Overlay denture temporary and permanent 
with $C D$ is challenging to the professional.

The difficulties occur in relation to denture stability and retention, since physical factors, such as adhesion, surface tension and cohesion are impaired. Other aspects to be considered are the alveolar ridge anatomy, presence of fistula or unrepaired cleft, which may favor the penetration of air and denture displacement. These individuals receive the denture with aesthetic, functional and obturator functions, improving the comfort, speech and psychological condition (Figure 7).

In operated individuals without fistula, the obturator function is not necessary, yet the alveolar ridge irregularity may compromise the denture stability. In operated individuals with fistula, the most frequent situation, the anterior region is more affected, which may influence the success of the denture.

Anatomical and functional impressions are obtained with variable degrees of complexity. In the anatomical impression, achieved with stock trays, the characteristics of the material depend on the remaining alveolar ridge. For open ridges with wide cleft, the material should be resilient to facilitate removal, such as condensation and addition silicones.

When fistulas are present, the indicated material for anatomical impression is high fusing compound, which does not pose the risk of material overflow, and tissue retraction allows visualization of the entire area that may be included in the denture base.

In palates without fistula, the high fusing compound may be used and relined or refined with alginate, enhancing the conditions for fabrication of the custom tray.

The subsequent steps follow the same principles for fabrication of $C D$ in individuals without clefts.

\section{IMPLANT-SUPPORTED DENTURE (ISD)}

For decades, the prosthetic rehabilitation of individuals with clefts has been related to the solution of sequels caused by surgical treatment without follow-up and inadequate dental procedures, which led to multiple and early losses. Therefore, the original dentures required complicated design and biomechanics, often leading to overload on the remaining teeth.

When osseointegration was discovered more than 50 years ago, it was not possible to calculate the benefits of this phenomenon to mankind. The edentulism in the cleft area in adult individuals, up to the mid-1980s, was solved with conventional dentures. Currently, the edentulous space may receive an implant and the denture. Complete or removable partial dentures with difficult retention in atresic maxillae may be replaced by fixed restorations or implant-supported overdentures.
The size, shape and location of the residual alveolar ridge in edentulous maxillae provide little support to the $C D$, thus impairing the retention and stability, often making them heavy due to extensions of the acrylic base in the vertical and horizontal directions. The presence of cleft with absence of the premaxilla further worsens this condition.

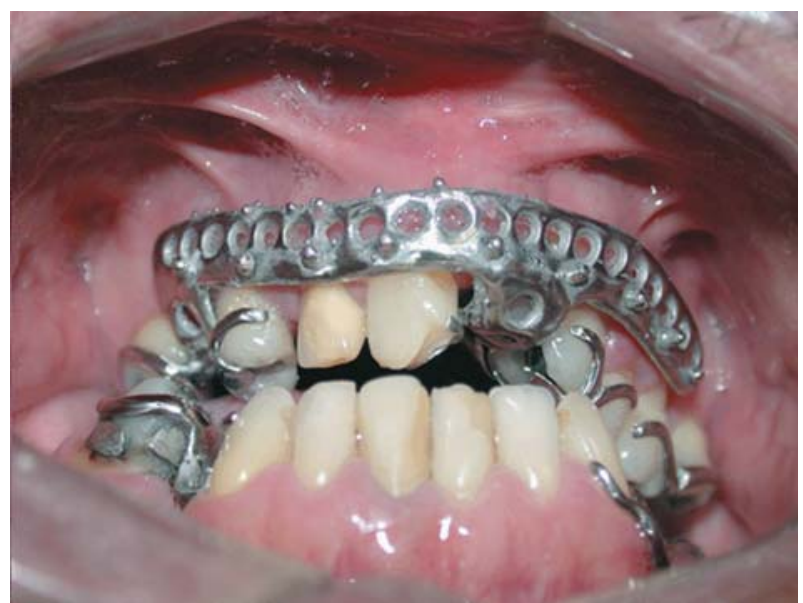

Figure 6- Proof of the overlay denture framework

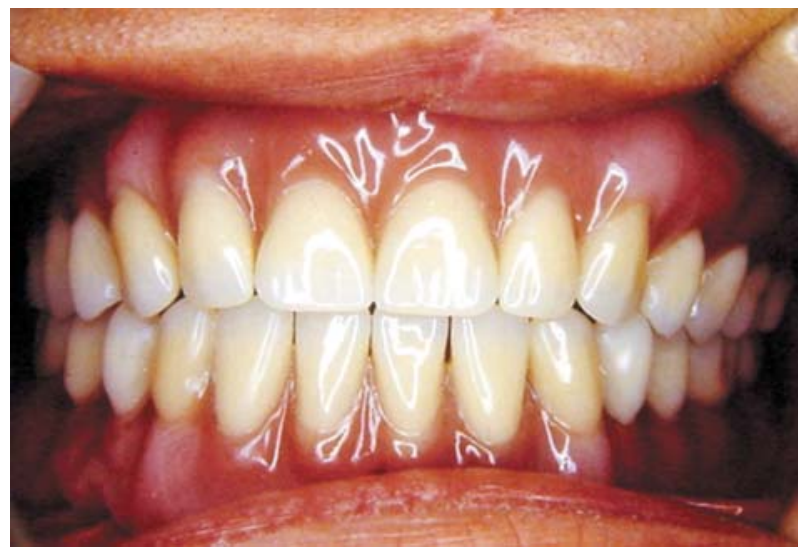

Figure 7- Frontal view of complete denture in position

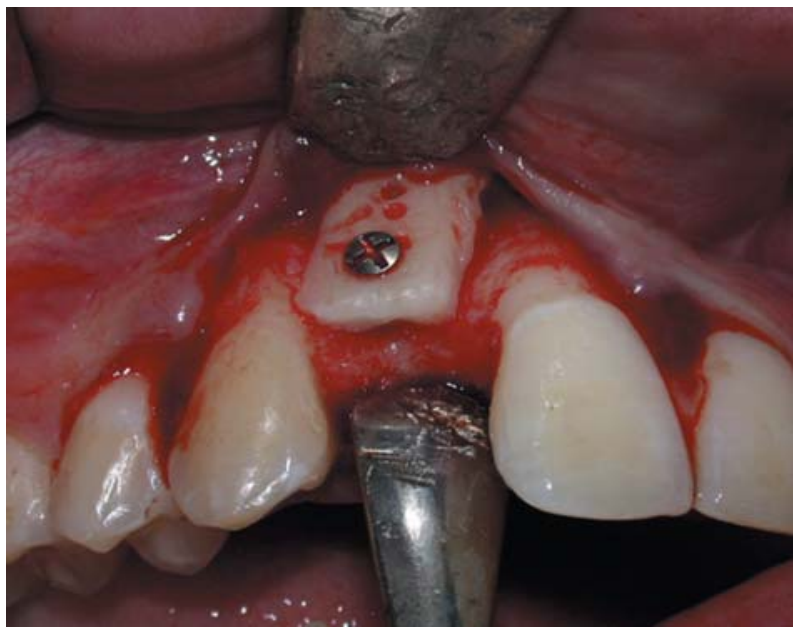

Figure 8- Re-graft area of the cleft area for dental implant 
In 1991, the first case report describing the complete technique for placement of an endosseous implant was published, 18 months after the alveolar cleft was grafted with cancellous autogenous bone from the tibia ${ }^{25}$.

Implant placement in the grafted bone provides a functional stimulus that is necessary to maintain the volume, preventing its resorption.

The alveolar bone graft is performed in young individuals before completion of development. Until the implants could be placed, this time period may lead to advanced resorption of grafts. Thus, re-graft of bone from the mandibular symphysis or oblique line of the mandible may be necessary to recover the thickness and height of the alveolar ridge in the area to be implanted (Figure 8 ).

There is consensus on the ideal period between alveolar bone graft and implant placement, of nearly 4 to 6 months to allow maintenance of sufficient bone volume for placement of well-positioned implants with proper dimensions.

When orthodontic finalizes the treatment leaving the space for implant placement in the grafted cleft area, sufficient bone thickness is necessary in the mesiodistal and buccolingual directions.

The success of implants placed in the grafted cleft area has been similar to the other areas, around $90 \%{ }^{9}$ (Figure 9).

The great challenge concerns the aesthetics in the implant region, because in many cases, even after bone graft, defects remain that may prevent or preclude the implant placement. In those cases, the option would be a fixed denture with artificial ceramic gingiva to mask the defect, even though in many cases the individual does not expose the gingival tissue during smiling ${ }^{8}$.

There is no doubt on rehabilitation with implantsupported dentures. However, an aspect that should be addressed for treatment optimization is the frequent impairment of soft tissue aesthetics in the cleft area. The absence of keratinized mucosa and absence of papilla may cause discomfort for oral hygiene and also social constraints when the individual smiles and exhibits the deficient gingival tissue ${ }^{7,10}$.

The care in soft tissue handling should be followed since the primary cleft repair, passing through surgeries for graft, implant placement and prosthetic intermediates, to allow more predictable achievement of the so-called "pink esthetics" related to the contour, shape, shade and position of the peri-implant gingival margin similar to the adjacent teeth ${ }^{10}$.

The vestibuloplasty technique associated with free gingival graft is widely used both in the cleft area and in other areas rehabilitated with implantsupported dentures for achievement of high-quality soft tissue and consequent homeostasis of these tissues $^{4,18,19}$.

\section{SPEECH APPLIANCE OR PALATAL PROSTHESIS}

Individuals with cleft lip and palate may often present speech problems due to the presence of fistula, unrepaired palate or some situations that can damage the appropriate closure of the velopharyngeal valve. The velopharynx is a tridimensional muscular valve located between the oral and nasal cavities that control the passage of air between mouth and nose.

The velopharyngeal dysfunction may occur when the velopharynx valve is unable to perform its own closing, due to lack of tissue (velopharyngeal insufficiency) or even lack of proper movement (velopharyngeal incompetence) $)^{20,21}$.

Particularly in cases of individuals with cleft lip and palate, most are related to velopharyngeal insufficiency, considering the lack of tissue on the soft palate, presence of fistula or even due to conditions in which the palate remains open. The constant communication between the oral and nasal cavities damage the speech intelligibility, as well as the absent or weak intraoral pressure, hypernasality, compensatory articulation, and nasal air emission. The speech of individuals with cleft palate is primarily characterized by abnormalities in nasal resonance. In addition, there may be articulation errors, including compensatory articulations and a reduction in speech intelligibility ${ }^{20}$.

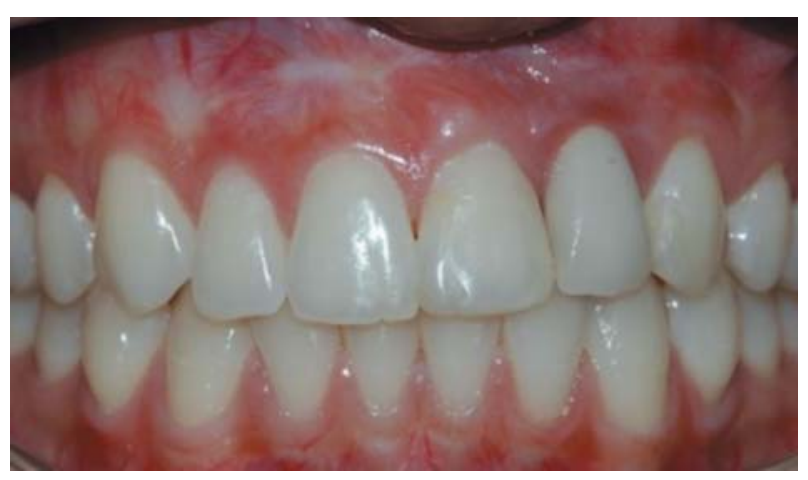

Figure 9- Implant in the left lateral incisor

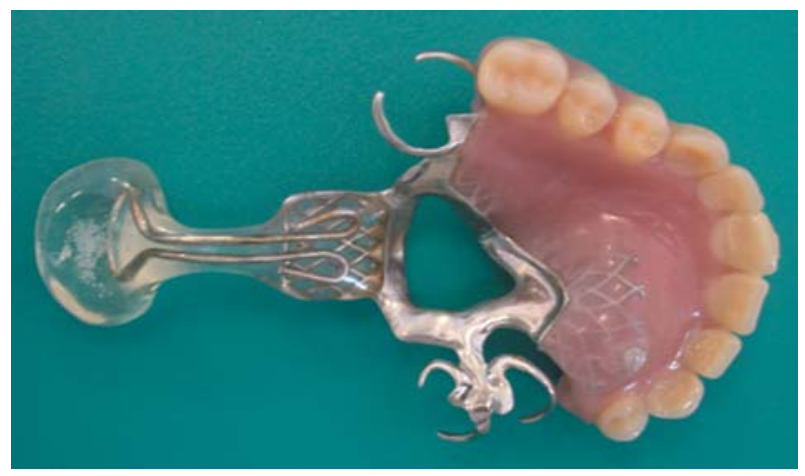

Figure 10- Palatal prosthesis 
Velopharyngeal dysfunction may be treated by speech therapy, surgery, prosthesis or a combined approach. Although the surgeries (palatoplasty and pharyngoplasty) are the procedures more often used, speech appliances or palatal prostheses are important treatment options for velopharyngeal dysfunction.

The speech prosthesis may be the best choice in several situations, for example, when surgery may not be performed because of systemic, anatomic, or functional limitations or if the individual is not willing to undergo surgery. Another very common situation for indication of palatal prostheses for individuals with cleft lip and palate is when velopharyngeal dysfunction occurs in individuals with many missing teeth, requiring a complete or partial removable denture (Figure 10).

Children may also receive palatal prostheses as a treatment for velopharyngeal dysfunction and eventually stimulate the muscle movement of the lateral pharyngeal walls, aiming at a future surgery.

The palatal prosthesis or speech appliance can be didactically divided in three portions, anterior, intermediate and posterior. The anterior portion corresponds to the conventional denture, and it can be a removable partial denture, a complete denture, an overdenture or even an acrylic plate.

In some cases, the nasopharynx is so deep that it is necessary to consider an intermediate portion between these two (anterior and posterior) to properly place and retain the posterior portion. In some cases the intermediate may close the palate or fistulae, if necessary.

Fabrication of the posterior portion is initiated only after the individual has used the prosthesis with the intermediate portion. A brass wire is adapted to the end of the prosthesis to mold the posterior portion, which supports the impression compound. The wire is folded so that it forms a loop, attached to the prosthesis. A very good attachment is necessary to prevent denture loosening while molding is performed. A preliminary impression is initially taken, adapting the modeling compound to the metallic loop. When the material is still plastic, the denture is placed in the individual's mouth and the individual is properly asked by the speech pathologist to produce some phonemes, move the head and swallow. The enlargement of the prosthesis towards the pharynx must be gradual and very well tolerated by the individual, to avoid discomfort and a gagging reflex ${ }^{20,21}$.

The completion of anatomical impressions of the velopharynx is performed with wax or modeling compound, during the nasoendoscopy view. This examination consists of introducing an optic fiber though the individual's nose up to a point that allows a superior view of the velopharyn $x^{20,21}$.

The image is presented on a monitor and allows all the staff and even the individual to observe the molding process. After all adjustments, the impression is properly included in a master cast, and the posterior portion is also processed with heat-activated acrylic resin 20,21 .

Follow-up visits are initially indicated on a weekly basis and then monthly, up to the individual's discharge, usually six months after treatment onset. The main purpose of physical or behavioral



Figure 11- Presence of frenula, gingival recession on teeth adjacent to the cleft and generalized dental plaque



Figure 12- Malpositioned tooth close to the cleft

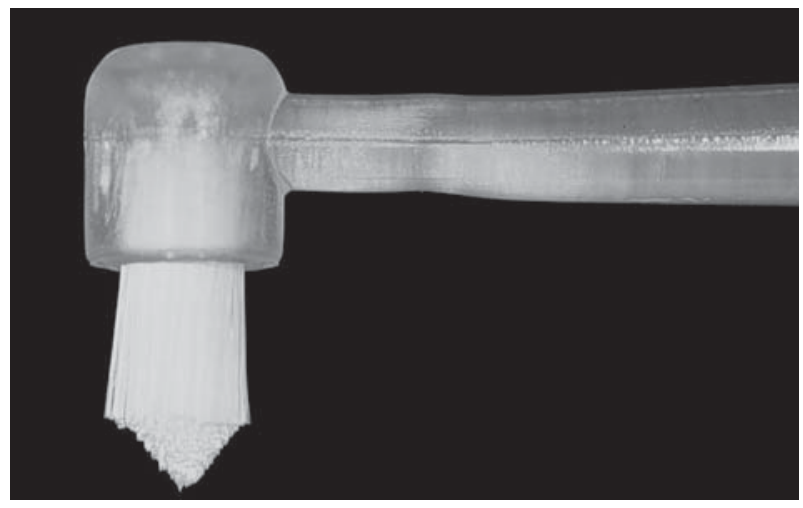

Figure 13- Single-tufted toothbrush indicated for hygiene of malpositioned teeth adjacent to the cleft 
management in individuals with cleft lip and palate is the achievement of intelligible speech of pleasing quality.

Therefore, it may be concluded that palatopharyngeal obturators and pharyngeal bulbs improve the ability to maintain intraoral air pressure, improving the speech intelligibility. Speech therapy is needed to eliminate any compensatory articulation productions developed prior to prosthetic management ${ }^{20,21}$.

\section{ROLE OF PERIODONTOLOGY IN ORAL REHABILITATION}

Current periodontology plays a fundamental role in the oral and systemic health of individuals, either with or without clefts. It acts both on the prevention of gingivitis and periodontitis, on the treatment of established diseases and maintenance of homeostasis of periodontal tissues.

Several factors contribute to the difficult oral hygiene of teeth close to the cleft area, including presence of gingival recessions, frenula (Figure $11)$, tooth malpositioning (Figure 12), dental anomalies and extended use of fixed orthodontic appliances ${ }^{1-5,24}$.

The periodontology acts in combination with community health for oral hygiene instructions and control, during surgical, orthodontic and rehabilitative treatment.

Even though some studies report that teeth adjacent to the cleft area are more susceptible to periodontal disease, a real relationship has not been found between the risk of disease and the presence of cleft lip and palate. It has been observed that the individual may or may not be susceptible to periodontitis, and the presence of disease is not dependent on whether the site is close to or not to the cleft. It has been described that these teeth present a longer connective attachment, yet there is no contraindication to their utilization as abutments during the rehabilitative process.

Regardless of the type of oral rehabilitation to which the individual will be submitted, the periodontal treatment is performed by two different conditions, if the individual is susceptible or not. If the individual is not susceptible to periodontitis, i.e. presenting only gingivitis, dental plaque control is indicated by oral hygiene instructions, crown and root scaling and planning and professional prophylaxis following the individual's schedule.

Throughout the dental treatment the individual should be controlled as to the oral hygiene conditions, with supervised toothbrushing in the Community Dentistry or Periodontology sectors. The techniques are the same, as well as the indication of toothbrushes, toothpaste and floss, with the addition of single-tufted toothbrushes to facilitate the plaque removal in teeth adjacent to the cleft
(Figure 13).

In the case of susceptibility, the individual receives the same aforementioned treatment combined with surgical therapies that may be mucogingival, resective or regenerative.

Surgical therapies performed more frequently in individuals with clefts are gingivoplasty, gingivectomy, free or pediculated gingival graft, vestibule deepening with or without free gingival graft, removal of frenula, and restoration of biological dimensions.

\section{CONCLUDING REMARKS}

The rehabilitation of individuals with cleft lip and palate often requires an interdisciplinary approach comprising at least medical and dental doctors and speech pathologists, to allow adequate aesthetic and functional conditions to the individual.

The rehabilitative and prosthetic treatment of individuals with cleft lip and palate is one of the last treatment stages, after growth completion, finalization of orthodontic treatment and the main surgeries. The type of denture should be indicated according to the need of each individual and according to the oral and systemic health, besides the individual's expectations.

\section{REFERENCES}

1- Almeida ALPF, Esper LA, Kaizer RO, Fernandes JS, Greghi SL, Carrilho GP. Surgical treatment of mucogingival alterations in cleft lip and palate patients: a clinical report. Perio. 2006;3:31-5. 2- Almeida ALPF, Esper LA, Pegoraro TA, Valle AL. Gingival recession in individuals with cleft lip and palate: prevalence and severity. Cleft Palate J. 2012;49:92-5.

3- Almeida ALPF, Madeira LC, Freitas KC, Greghi SL, Pegoraro LF. Cross-sectional evaluation of the presence of gingival recession in individuals with cleft lip and palate. J Periodontol. 2007;78:29-36. 4- Almeida ALPF, Pedro PF, Kogawa EM, Pereira T, Carrilho GP, Aiello $\mathrm{CA}$, et al. Comparative evaluation of two different vestibuloplasty surgical procedures in cleft patients: a pilot study. Cleft Palate J. 2005;42:439-441.

5- Almeida ALPF, Sbrana MC, Esper LA, Greghi SL, Conti PC. Gingival recession in maxillary canines and central incisors of individuals with clefts. Oral Surg Oral Med Oral Pathol Oral Radiol Endod. 2010;109:37-45.

6- Brasil JM, Pernambuco RA, Dalben GS. Suggestion of an oral hygiene program for orthodontic patient with cleft lip and palate: findings of a pilot study. Cleft Palate Craniofac J. 2007;44:595-7. 7- Esper LA, Ferreira SB Jr, Kaizer ROF, Almeida ALPF. The role of keratinized mucosa in peri-implant health. Cleft Palate Craniofac J. 2012;49:167-70.

8- Esper LA, Sbrana MC, Ribeiro IWJ, Siqueira EN, Almeida ALPF. Esthetic analysis of gingival components of smile and degree of satisfaction in individuals with cleft lip and palate. Cleft Palate Craniofac J. 2009;46:381-7.

9- Ferreira SB Jr, Esper LA, Sbrana MC, Ribeiro IWJ, Almeida ALPF. Survival of dental implants in the cleft area - a retrospective study. Cleft Palate Craniofac J. 2010;47:586-90.

10- Fiamengui Filho JF, Almeida ALPF. Esthetic analysis of implant-supported denture at the cleft area. Cleft Palate Craniofac J. 2012. Epub ahead of print. Available from: http://dx.doi. org/10.1597/11-193 
11- Freitas AC Jr, Silva AM, Lima Verde MA, Aguiar JR. Oral rehabilitation of severely worn dentition using an overlay for immediate re-establishment of occlusal vertical dimension. Gerontology. 2012;29(1):75-80.

12- Freitas JAS, Garib DG, Oliveira TM, Almeida ALPF, TrindadeSuedam IK, Yaedú RYF et al. Rehabilitative treatment of cleft lip and palate: experience of the Hospital for Rehabilitation of Craniofacial Anomalies/USP (HRAC/USP) - part 2: Pediatric Dentistry and Orthodontics. J Appl Oral Sci. 2012;20(2):272-85. 13- Freitas JAS, Neves LT, Almeida ALPF, Garib DG, TrindadeSuedam IK, Yaedú RYF, et al. Rehabilitative treatment of cleft lip and palate: experience of the Hospital for Rehabilitation of Craniofacial Anomalies/USP (HRAC/USP) - Part 1: overall aspects. J Appl Oral Sci. 2012; 20(1):9-15.

14- Fukuda M, Takahashi T, Yamaguchi T, Kochi S, Inai T, Watanabe $M$, et al. Dental rehabilitation using endosseous implants and orthognathic surgery in patients with cleft lip and palate: report of two cases. J Oral Rehabil. 2000;27:546-51.

15- Hickey AJ, Salter M. Prosthodontic and psychological factors in treating patients with congenital and craniofacial defects. J Prosthet Dent. 2006;95:392-6.

16- Lopes JFS, Pinto JHN, Almeida ALPF, Lopes MMW, Dalben GS. Cleft palate obturation with Brånemark protocol implant-supported fixed denture and removable obturator. Cleft Palate Craniofac J. 2010;47:211-5.

17- Mazaheri M. Indications and contraindications for prosthetic speech appliances in cleft palate. Plast Reconstr Surg Transplant Bull. 1962;30:663-9.

18- Melo LGN, Almeida ALPF, Lopes JFS, Rezende ML, Neto JS, Ciporkin $\mathrm{F}$, et al. A modified approach for vestibuloplasty in severely resorbed mandible using an implant-retained postoperative stent: a case report. Oral Surg Oral Med Oral Pathol Oral Radiol Endod. 2008; 106:e7-14.
19- Melo LGN, Ciporkin F, Neto JS, Almeida ALPF, Lopes JFS, Figueiredo $\mathrm{CM}$, et al. Correction of mucogingival defect using an implant-retained postoperative stent in a severely resorbed mandible: case report. Int J Periodontics Restorative Dent. 2008;28:617-23.

20- Pinto JHN, Dalben GS, Pegoraro-Krook MI. Speech intelligibility of patients with cleft lip and palate after placement of speech prosthesis. Cleft Palate Craniofacial J. 2007;44(6):635-41.

21- Pinto JHN, Pegoraro-Krook MI. Evaluation of palatal prosthesis for treatment of velopharyngeal dysfunction. J Appl Oral Sci. 2003; 11:192-7.

22- Reisberg DJ. Dental and prosthodontic care for patients with cleft or craniofacial conditions. Cleft Palate Craniofacial J. 2000;37:534-7.

23- Reisberg DJ. Prosthetic rehabilitation of patients with clefts. Clin Plast Surg. 2004;31:353-60.

24- Ruiz LA, Maya RR, D'Alpino PHP, Atta MT, Svizzero NR. Prevalence of enamel defects in permanent teeth of patients with complete cleft lip and palate. Cleft Palate Craniofac J. 2012. Epub ahead of print. Available from: http://dx.doi.org/10.1597/11-200 25- Verdi FJ Jr, Lanzi GL, Cohen SR, Powell R. Use of the Brånemark implant in the cleft palate patient. Cleft Palate Craniofac J. 1991;28:301-3.

26- Watanabe I, Kurtz KS, Watanabe E, Yamada M, Yoshida N, Miller AW. Multi-unit fixed partial denture for a bilateral cleft palate patient: a clinical report. J Oral Rehabil. 2005;32:620-2.

27- Wirz J Prosthetic planning and therapy for repaired cleft lip, maxilla and palate patients. Quintessence Int. 1971;2:57-61.

28- Zhou W, Li W, Lin J, Liu D, Xie X, Zhang Z. Tooth lengths of the permanent upper incisors in patients with clefts lip and palate determined with cone bean computed tomography. Cleft Palate Craniofac J. 2013;50:88-95. 